\title{
PESQUISADORES BRASILEIROS E AS POSSIBILIDADES DE USO DE SMARTPHONE NAS AULAS DE MATEMÁTICA
}

\author{
BRAZILIAN RESEARCHERS AND THE POSSIBILITIES OF SMARTPHONE USAGE IN MATH CLASSES \\ INVESTIGADORES BRASILEÑOS Y LAS POSIBILIDADES DE USAR UN TELÉFONO INTELIGENTE EN \\ LAS CLASES DE MATEMÁTICAS
}

\author{
Ana Paula de Andrade Janz Elias \\ Mestre em Ensino de Ciências e Matemática Universidade Tecnológica Federal do Paraná. \\ E-mail: anapjaz777@gmail.com. \\ Orcid: https://orcid.org/0000-0002-6494-9448.
}

\begin{abstract}
Flavia Sucheck Mateus da Rocha
Mestre em Educação em Ciências e Matemática - UFPR. Doutoranda em Educação em Ciências e Matemática UFPR.

E-mail: fsucheck@yahoo.com.br.

Orcid: https://orcid.org/0000-0001-6803-8898.
\end{abstract}

\author{
Taniele Loss \\ Doutoranda em Ensino De Ciências e Matemática - UTFPR. \\ E-mail: tani_loss@hotmail.com. \\ Orcid: https://orcid.org/0000-0002-0384-3260.
}

\section{Marcelo Souza Motta}

Professor Programa de Pós-Graduação em Formação Científica, Educacional e Tecnológica (PPGFCET). Programa de Pós-Graduação em Educação em Ciência E Matemática (PPGECM). Doutor em Ensino de Ciências e Matemática.

E-mail: msmotta27@gmail.com.

Orcid https://orcid.org/0000-0001-5534-2735

\begin{abstract}
RESUMO
Diferentes tecnologias digitais podem ser inseridas no contexto educacional para auxiliar os processos de ensino e de aprendizagem nos tempos atuais. Considerando que os smartphones representam uma destas possibilidades, alguns pesquisadores têm direcionado suas investigações para essa temática. Nesse viés, o presente estudo objetivou identificar os caminhos percorridos e as considerações levantadas por pesquisadores brasileiros que estão inseridos em programas de pós-graduação stricto sensu, que tratam sobre a utilização de aparelhos smartphones em aulas de Matemática. Foi realizado uma revisão sistemática, tendo como foco, dissertações de mestrado profissional disponibilizadas no Banco de Teses e Dissertações da Capes. Dessa revisão, 15 dissertações foram selecionadas para análise. A pesquisa identificou que grande parte dos trabalhos analisados apontam que os smartphones podem ser utilizados em sala de aula por meio de aplicativos educacionais. Além disso, foi possível perceber lacunas de investigações, pois não foram encontrados textos que tratassem da Educação Superior.
\end{abstract}

Palavras-chave: Ensino de matemática. Smartphones. Revisão sistemática. Pesquisas brasileiras.

\section{ABSTRACT}

Different digital technologies can be inserted in the educational context to assist with the teaching and learning processes in the current times. Considering that smartphones represent one of these possibilities, some researchers have directed their investigations approaching this theme. In this sense, the present study 
aimed to identify the paths taken and the considerations raised by Brazilian researchers who are inserted in stricto sensu graduate programs, which deal with the usage of smartphones in math classes. A systematic review was carried out, focusing on professional master's dissertations available at Capes thesis and dissertations database. In this review, 15 dissertations were selected for analysis. The research identified that a large part of the studies analyzed indicate that smartphones can be used in the classroom through educational applications. In addition, it was possible to perceive research gaps, as no texts found handle with Higher Education.

Keywords: Mathematics teaching. Smartphones. Systematic review. Brazilian research.

\section{RESUMEN}

Se pueden insertar diferentes tecnologías digitales en el contexto educativo para ayudar con los procesos de enseñanza y aprendizaje en los tiempos actuales. Teniendo en cuenta que los teléfonos inteligentes representan una de estas posibilidades, algunos investigadores han dirigido sus investigaciones a este tema. En este sentido, el presente estudio tuvo como objetivo identificar los caminos tomados y las consideraciones planteadas por los investigadores brasileños que se insertan en programas de posgrado estrictamente sensuales, que se ocupan del uso de dispositivos de teléfonos inteligentes en las clases de Matemáticas. Se realizó una revisión sistemática, centrada en las tesis de maestría profesional disponibles en el Capes Thesis and Dissertations Bank. De esta revisión, se seleccionaron 15 tesis para el análisis. La investigación identificó que gran parte de los estudios analizados señalan que los teléfonos inteligentes se pueden usar en el aula a través de aplicaciones educativas. Además, fue posible percibir lagunas en la investigación, ya que no se encontraron textos relacionados con la Educación Superior.

Palabras clave: Enseñanza de las matemáticas. Teléfonos inteligentes. Revisión sistemática. Investigación brasileña.

\section{INTRODUÇÃO}

A sociedade está vivenciando um momento histório no qual se faz necessário mudanças constantes em diferentes cenários: econômico, político, cultural, ideológico e tecnológico (URBANO; FARÍAS; PÉREZ, 2019). Nesse viés, as Tecnologias Digitais (TD) se fazem cada vez mais presentes no cotidiano dos seres humanos, modificando a maneira como cada um vive, se expressa, se relaciona e até mesmo como aprende. Entre as Tecnologias Digitais mais utilizadas na atualidade estão os aparelhos smartphones. Crianças, jovens e adultos fazem uso desses recursos, inclusive em locais de trabalho e de estudo. Desse modo, é possível notar que mesmo no ambiente escolar, alguns estudantes estão constantemente equipados com o smartphone. Freitas e Carvalho (2017) apontam que:

Diante de uma sociedade em que a informação está dentro de um smartphone, no qual diversas tarefas podem ser acessadas por simples toques na tela touchscreen implica em repensar a sala de aula como o único espaço para aprender e ensinar, isso porque, o aluno, orientado pelo seu professor pode acessar na internet a informação necessária para que complemente as suas aprendizagens matemáticas e dialogar com colegas e o professor sobre o que aprender acerca de determinado conteúdo matemático (FREITAS; CARVALHO, 2017, p. 48). 
Com o que foi apontado pelos autores supracitados e, ao considerar a necessidade de o sistema educacional e de os diferentes atores que compõe esse sistema buscarem estratégias e metodologias que valorizem os saberes dos estudantes, e ainda, ao ponderar sobre a necessidade de, enquanto instituição escolar, se deve preparar o estudante para uma atuação efetiva na sociedade na qual ele está inserido, é possível fazer uma reflexão sobre a inserção de smartphones em sala de aula, como possibilidade pedagógica. Pois, como o smartphone é uma tecnologia digital, é possível afirmar que ele, assim como as demais tecnologias digitais, pode ser um grande aliado nos processos de ensino e de aprendizagem (MENDES; CHAMPAOSKI, 2017).

No contexto educacional o professor pode fazer uso do smartphone, que é um recurso que já faz parte do cotidiano do estudante, como ferramenta de apoio e de auxílio na construção do conhecimento. Entretanto, ocorre uma limitação do uso desses aparelhos no meio educacional devido a falta de conhecimentos pedagógicos e de uma legislação a níveis federal e estadual. Até o momento da realização dessa pesquisa, foi identificado apenas três estados brasileiros que permitem legalmente o uso pedagógico de smartphones dentro da escola: Paraná, São Paulo e Mato Grosso.

Destarte, este artigo teve como objetivo inicial verificar o que tem sido desenvolvido de produção acadêmica em relação ao uso dos aparelhos smartphones nas aulas de Matemática na atualidade, bem como verificar se o uso desse recurso pode efetivamente auxiliar os estudantes no aprendizado dessa disciplina.

É possível afirmar que utilizar-se de diferentes ferrametnas para auxiliar na compreensão dos conteúdos matemáticos é um dever e um desafio aos professores que atuam em escolas brasileiras, porém, é efetivamente possível e viável isto nos dias atuais? O que os pesquisadores da atualidade têm investigado e apontado em relação à utilização de smartphones no contexto educacional? Para responder a esses questionamentos foi realizada uma revisão sistemática a partir do banco de teses e dissertações da Capes, dos trabalhos mais recentes sobre esse assunto para mapear o que tem sido discutido. 
A revisão, citada anteriormente, aconteceu no primeiro semestre do ano de 2019. Para análise dos dados, o software ATLAS. $\mathrm{ti}^{1}$ foi utilizado como suporte, o que possibilitou a criação de códigos para melhor compreensão do que tem sido tratado nos trabalhos selecionados, bem como permitiu uma visualização mais efetiva dos dados, a partir das redes criadas a partir do software. Foi possível identidicar no ATLAS.ti uma ferramenta com potencial para auxiliar os pesquisadores a focar seus esforços na análise, na interpretação dos dados e no processo de revisão dos resultados obtidos.

\section{Utilização de smartphones nas aulas de Matemática}

O uso de diferentes tecnologias é percebido nos mais diversos meios sociais. Tal ação tem influenciado as pessoas e tem possibilitado à elas mudanças nas formas de agir, fazer, viver e até na maneira de aprender (MALTEMPI, 2005). Essas mudanças sociais intereferem nos diferentes ambientes educacionais pois, a instituição escola está intimamente ligada a sociedade na qual está inserida. Diante disso, essa instituição deve preparar os indivíduos que por ela passam para uma atuação efetivamente consciente e ativa dentro do ambiente que vivem e convivem. "Precisa-se quebrar alguns paradigmas e reconhecer a necessidade de trazer a tecnologia digital para dentro da sala de aula para promover uma educação de qualidade e que atenda a demanda do atual contexto que vivemos" (HESS; ASSIS; VIANA, 2019, p. 120).

A humanidade busca adaptações que tragam mais conforto para seu agir diário e, por isso cria ferramentas e processos que podem ser considerados tecnologias. Essas ferramentas e processos, inclusive relacionados as Tecnologias Digitais (TD), acabam adentrando o ambiente educacional, seja de maneira intencional ou não.

Relacionado especificamente à Educação Matemática, Borba, Silva e Gadanidis (2015) destacam quatro fases sobre o uso das TD. Essas fases foram citadas por Elias (2018) em sua dissertação de mestrado e, podem ser identificadas na Figura 1:

Figura 1 - Fases das TD na Educação Matemática

\footnotetext{
1 "O software Atlas.ti consiste em uma ferramenta para a análise de dados qualitativos que pode facilitar o gerenciamento e a informação desses dados" (WALTER; BACH, 2015, p. 275).
} 


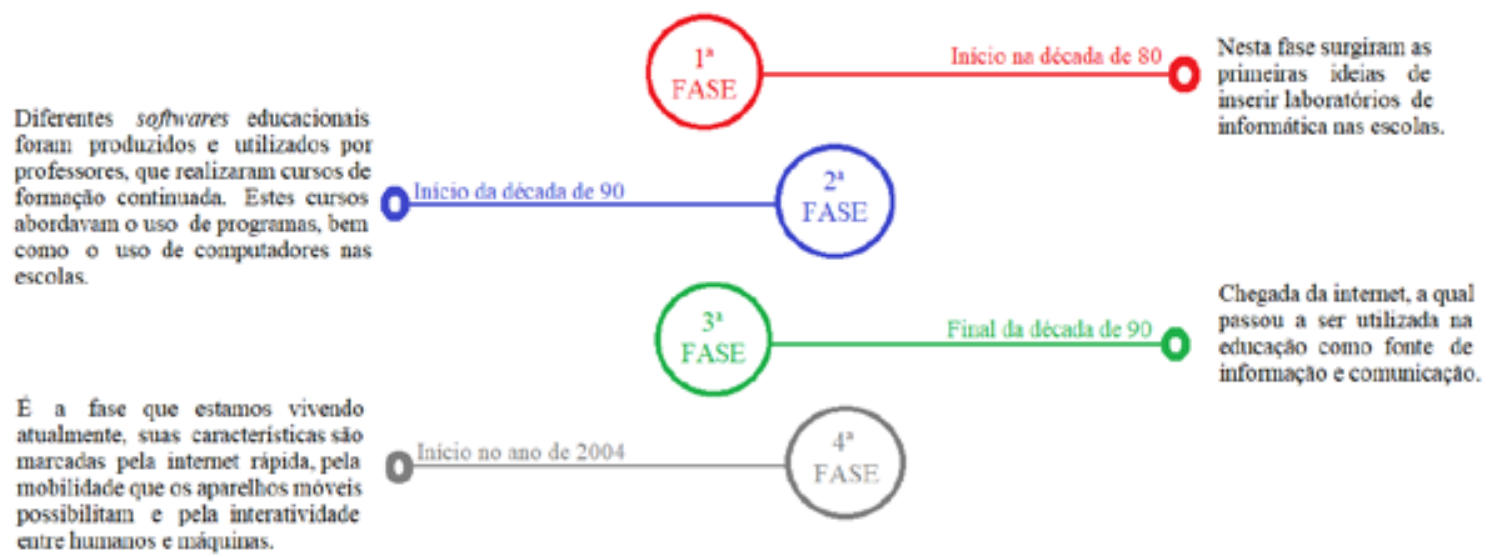

Fonte: Elias (2018, p. 22)

$\mathrm{Na}$ quarta fase novas possibilidades começam a fazer parte do rol de recursos direcionados para o ensino e para a aprendizagem de Matemática, como: vídeos digitais; softwares de programação; e smartphones. Mesmo sendo visto como recurso didático por alguns autores, inclusive Borba e Lacerda (2015), o uso de smartphones em sala de aula ainda é proibido em alguns estados brasileiros, o que demonstra a necessidade de realização e divulgação de pesquisas sobre essa temática. Tais pesquisas podem contribuir com a compreensão acerca das potencialidades que práticas pedagógicas com smartphones representam, além de alavancarem discussões que repercutam em políticas públicas e legislações específicas. Também é possível perceber que pesquisas nesse viés podem incentivar professores a fazerem uso dessa tecnologia, já que segundo Romanello (2016, p. 32) “[...] há um grande atrito entre professores e alunos com relação a utilização dos celulares em sala de aula". Contudo, fazer uso sem um objetivo coerente, não garante que os resultados serão favoráveis aos processos de ensino e de aprendizagem (HESS; ASSIS; VIANA, 2019). Com isso, justifica-se novamente a realização de pesquisas que indiquem como estão sendo desenvolvidas atividades a partir do uso de smartphones dentro dos espaços escolares.

Romanello (2016, p.33) também comenta que “já é perceptível que o cotidiano de muitos dos alunos está permeado de tecnologias, como é o caso dos celulares [...]”. Grande parte dos estudantes já possuem esses aparelhos e os carregam para todos os ambientes que frequentam, inclusive para a escola pois, “o telefone celular já pode ser visto como uma extensão do nosso corpo [...]" (BORBA; LACERDA, 2015, p.10). 
Conforme pontuam Almeida, et al. (2019, p. 206), “o novo perfil de alunos na contemporaneidade instiga um repensar das metodologias e estratégias didática, pois eles desejam participar mais ativamente [...]" dos processos de construção do conhecimento. Também considerando a familiaridade que os estudantes possuem com os aparelhos smartphones, é possível identificar que o uso pedagógico dessa tecnnologia pode propiciar momentos diferenciados nos processos educativos da Matemática.

Vale pontuar que não basta inserir o smartphone em sala de aula e esperar que ele, por si só, possa modificar os processos pedagógicos e melhorar o processo de aprendizagem aprendizagem de Matemática. Kenski, já no ano de 2003 comentava sobre as especificidades que cada tecnologia possui e, a autora apontava para a necessidade de uma utilização apropriada das tecnologias por parte dos professores.

\section{Aspectos metodológicos}

Para identificar os apontamentos e caminhos percorridos pelas pesquisas brasileiras de mestrado profissional sobre a utilização do smartphone em aulas de Matemática, foi realizada uma revisão sistemática, no primeiro semestre do ano de 2019. A escolha pelas dissertações de mestrado profissional se deu devido ao fato de que os alunos desses cursos são, em sua maioria, profissionais que atuam em sala de aula. Ou seja, esses pesquisadores/profissionais realizaram suas pesquisas dentro do ambiente educacional e tiveram a possiblidade de investigar a partir do trabalho que foi efetivamente desenvolvido no contexto educacional. E ainda, vale salientar que no mestrado profissional, faz-se necessário a produção de um produto educacional. Esse produto pode ser disponibilizado a diferentes docentes que atuam nas escolas brasileiras.

A escolha pela revisão sistemática se deu porque os recortes que ela possibilita orientam a análise dos trabalhos selecionados (VOSGERAU; ROMANOWSKI, 2014). Os autores Ramos, Faria e Faria (2014) comentam que:

no processo de revisão sistemática de literatura, é imprescindível que sejam registradas todas as etapas de pesquisa, não só para que esta possa ser replicável por outro investigador, como também para se aferir que o processo em curso segue uma série de etapas previamente definidas e absolutamente respeitadas nas várias etapas (RAMOS, FARIA, FARIA, 2014, p. 23). 
A primeira etapa de uma revisão sistemática consiste na formulação de uma pergunta que dê norte à pesquisa. Nessa investigação, a pergunta levantada e que necessitava de resposta foi: Quais os caminhos percorridos e considerações levantadas por pesquisadores inseridos em programas de pós-graduação das universidades brasileiras, sobre a utilização de aparelhos smartphones no contexto das aulas de Matemática? Foi escolhido o Banco de Teses e Dissertações da Capes para realizar o levantamento dos trabalhos desenvolvidos a partir desta temática. A escolha desse banco se deu porque nele estão contemplados teses e dissertações realizadas em todo o contexto educacional brasileiro.

Dois descritores foram utilizados para a busca no Banco de Teses e Dissertações da Capes: "smartphone" e "matemática”. Em um primeiro momento, foram identificadas 48 dissertações de mestrado. Foi possível notar que a base de dados pesquisada não possibilitou refinar a busca por "teses". Diante disso, houve a compreensão de que não havia no momento da investigação pesquisas de doutoramento concluídas sobre o uso de aparelhos smartphones nas aulas de Matemática. A busca foi refinada a partir da opção de “mestrado profissional”, pelos motivos já apontados anteriormente. Assim, 26 resultados foram obtidos.

Desses trabalhos, foi feita a leitura dos títulos e verificado que sete deles não apresentavam relação com o objetivo deste artigo pois: três abordavam o uso de smartphones nas aulas de Física; um tratava de questões relacionadas a inclusão escolar; um estava vinculado à área de enfermagem; um abordava apenas situações relacionadas à informática e não envolvia a disciplina de Matemática; e o sétimo investigava a anatomia humana. Sendo assim, foram excluídas essas dissertações, restando 19 trabalhos. Após houve o processo de leitura flutuante dos resumos das pesquisas e, nesse processo, foi possível perceber que quatro trabalhos não se adequavam à investigação aqui proposta: um estava direcionado à disciplina de eletrostática e três não apresentavam pesquisa empírica, apenas o produto educacional.

Diante disso, foram incluídas 15 dissertações para serem analisadas, conforme destacado no Quadro 1.

Quadro 1 - Dissertações selecionadas

\begin{tabular}{|l|c|l|}
\hline \multicolumn{1}{|c|}{ TíTULO DA DISSERTAÇÃO } & REFERÊNCIA & \multicolumn{1}{|c|}{ INSTITUIÇÃO } \\
\hline $\begin{array}{l}\text { Calculadora financeira HP - 12c em smartphones } \\
\text { como recurso didático para o ensino de matemática } \\
\text { financeira no ensino médio }\end{array}$ & AMARAL (2017) & $\begin{array}{l}\text { Universidade Federal } \\
\text { do Oeste do Paraná }\end{array}$ \\
\hline GeoGebra no clique e na palma das mãos: & HENRIQUE (2017) & Universidade Rural do \\
\hline
\end{tabular}




\begin{tabular}{|c|c|c|}
\hline $\begin{array}{l}\text { contribuições de uma dinâmica de aula para } \\
\text { construção de conceitos geométricos com alunos } \\
\text { do Ensino Fundamental }\end{array}$ & & Rio de Janeiro \\
\hline $\begin{array}{l}\text { Uso de princípios básicos de programação como } \\
\text { alternativa para o ensino de sistemas lineares e } \\
\text { matrizes no ensino médio }\end{array}$ & FONSECA (2017) & $\begin{array}{l}\text { Universidade Rural do } \\
\text { Rio de Janeiro }\end{array}$ \\
\hline $\begin{array}{l}\text { Um olhar etnomatemático acerca da utilização dos } \\
\text { smartphones nos processos de ensino de } \\
\text { matemática nos anos finais do ensino fundamental }\end{array}$ & GERSTBERGER (2017) & $\begin{array}{l}\text { Centro Universitário } \\
\text { Univates }\end{array}$ \\
\hline $\begin{array}{l}\text { Ensino da análise combinatória por meio de um } \\
\text { aplicativo para Android }\end{array}$ & TAVARES (2017) & $\begin{array}{l}\text { Pontifícia } \\
\text { Universidade Católica } \\
\text { de Minas Gerais }\end{array}$ \\
\hline $\begin{array}{l}\text { Tomada de decisões e o aprendizado de } \\
\text { matemática financeira: uma experiência com } \\
\text { aplicativos para smartphone }\end{array}$ & AMIM JUNIOR (2018) & $\begin{array}{l}\text { Universidade Federal } \\
\text { de Goiás }\end{array}$ \\
\hline $\begin{array}{l}\text { Potencialidades da utilização do software GeoGebra } \\
\text { para o desenvolvimento do conteúdo de funções } \\
\text { exponenciais através do smartphone }\end{array}$ & CRUZ (2018) & $\begin{array}{l}\text { Universidade Federal } \\
\text { de Ouro Preto }\end{array}$ \\
\hline $\begin{array}{l}\text { Utilização do GeoGebra, de smartphone e de } \\
\text { reflexões escritas na construção de conceitos } \\
\text { relacionados a retas paralelas cortadas por uma } \\
\text { transversal }\end{array}$ & DUARTE (2018) & $\begin{array}{l}\text { Universidade Federal } \\
\text { Rural do Rio de } \\
\text { Janeiro }\end{array}$ \\
\hline $\begin{array}{l}\text { Possibilidades de utilização de smartphones em sala } \\
\text { de aula: construindo aplicativos investigativos para } \\
\text { o trabalho com equações do } 2^{\circ} \text { grau }\end{array}$ & ELIAS (2018) & $\begin{array}{l}\text { Universidade } \\
\text { Tecnológica Federal } \\
\text { do Paraná }\end{array}$ \\
\hline $\begin{array}{l}\text { Dispositivos móveis no ensino de educação } \\
\text { financeira escolar: análise e aplicação de tarefas }\end{array}$ & FERNANDES (2018) & $\begin{array}{l}\text { Universidade Federal } \\
\text { de Juiz de For a }\end{array}$ \\
\hline $\begin{array}{l}\text { Uso do software livre GeoGebra no smartphone } \\
\text { como ferramenta de ensino e aprendizagem }\end{array}$ & LIMA (2018) & $\begin{array}{l}\text { Universidade Federal } \\
\text { do Pará }\end{array}$ \\
\hline $\begin{array}{l}\text { Teoria dos números e criptografia RSA: uma } \\
\text { proposta de ensino para alunos de matemática } \\
\text { olímpica }\end{array}$ & MACHADO (2018) & $\begin{array}{l}\text { Universidade Federal } \\
\text { de Santa Maria }\end{array}$ \\
\hline $\begin{array}{l}\text { O uso da calculadora gráfica GeoGebra no } \\
\text { smartphone como ferramenta para o ensino das } \\
\text { funções exponencial e logarítmica }\end{array}$ & NOGUEIRA (2018) & $\begin{array}{l}\text { Universidade Federal } \\
\text { do Rio Grande do } \\
\text { Norte }\end{array}$ \\
\hline $\begin{array}{l}\text { O uso da calculadora do cidadão em smartphones } \\
\text { como ferramenta didática no ensino da matemática } \\
\text { financeira no ensino médio }\end{array}$ & SANTOS (2018) & $\begin{array}{l}\text { Universidade Estadual } \\
\text { de Santa Cruz }\end{array}$ \\
\hline $\begin{array}{l}\text { A utilização do aplicativo GeoGebra para } \\
\text { smartphone como recurso didático nas aulas de } \\
\text { matemática do Ensino Fundamental }\end{array}$ & SILVA (2018) & $\begin{array}{l}\text { Universidade Federal } \\
\text { do Maranhão }\end{array}$ \\
\hline
\end{tabular}

Fonte: os autores (2020).

Foi realizado, no Banco de Teses e Dissertações da Capes, o download de cada um dos trabalhos no formato PDF e após, eles foram importados para o software ATLAS.ti. Sete códigos foram criados para análise das dissertações, com base no objetivo desta pesquisa: (i) abordagem utilizada; (ii) aplicativos investigados; (iii) conteúdo envolvido; (iv) nível de ensino; (v) referencial teórico; (vi) lei sobre uso de smartphone e (vii) resultados obtidos. Foi feita a leitura integral de cada dissertação, visando uma efetiva codificação de cada texto a partir dos códigos criados. Por fim, realizou-se a análise dos dados coletados. 


\section{Análise dos dados}

Para a pré-análise, foram criados sete códigos, conforme indicado anteriormente. Aqui é apresentado os resultados das buscas realizadas na leitura integral dos textos, a partir dos códigos criados.

Para o primeiro código, “abordagem utilizada”, seis autores optaram por uma abordagem qualitativa (GERSTBERGER, 2017; AMIM JUNIOR, 2018; CRUZ, 2018; ELIAS, 2018; FERNANDES, 2018; SANTOS, 2018); três indicaram que fizeram uma pesquisa de campo (AMARAL, 2017; DUARTE, 2018; LIMA, 2018); dois autores utilizaram a abordagem quantiqualitativa (LIMA, 2018; SILVA, 2018); um utilizou a pesquisa fundamentada (CRUZ, 2018); um autor utilizou a observação participante (FERNANDES, 2018); um realizou sua investigação a partir de um estudo de caso (FONSECA, 2017); um autor realizou a pesquisa chamada de design (HENIRQUE, 2017); um utilizou a pesquisa-ação (TAVARES, 2017); e um utilizou a metodologia da criptografia RSA (MACHADO, 2018). Aqui é possível perceber que o autor Cruz (2018) indicou duas abordagens utilizadas, bem como Lima (2018) e Fernandes (2018). O autor Nogueira (2018) foi o único que não indicou a abordagem que utilizou em sua pesquisa.

Em relação ao código "aplicativos investigados", foram encontrados 32 aplicativos diferentes, pois alguns autores das dissertações utilizaram mais de um aplicativo para realizar suas pesquisas (GERSTBERGER, 2017; TAVARES, 2017; AMIM JUNIOR, 2018; ELIAS, 2018; FERNANDES, 2018; LIMA, 2018; MACHADO, 2018). Dois aplicativos foram citados em mais de uma pesquisa: GeoGebra e Calculadora do Cidadão. Na Figura 2, é apresentado os aplicativos utilizados pelos autores dos trabalhos. 
Figura 2 - aplicativos identificados na revisão sistemática

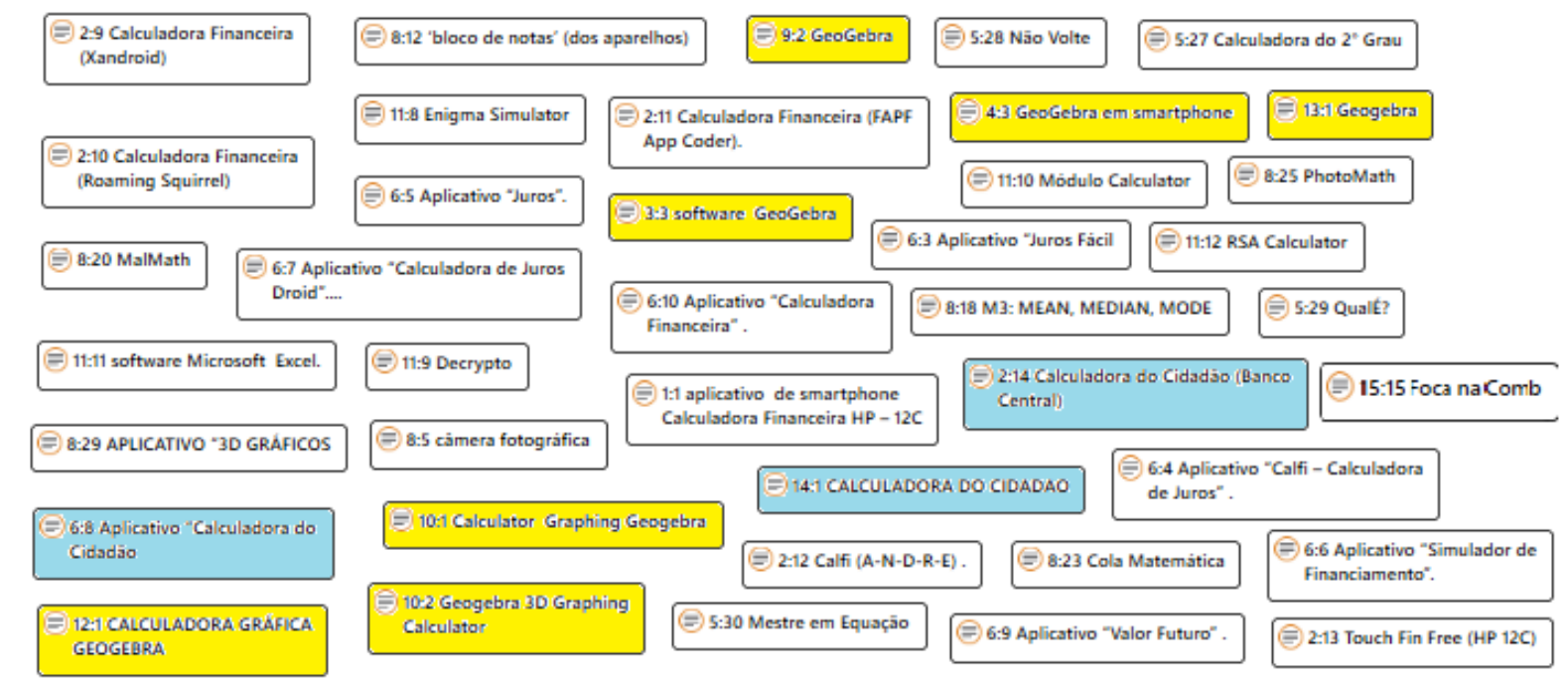

Fonte: dados da pesquisa (2019).

Dentre os aplicativos utilizados, cinco foram construídos pelos próprios pesquisadores, por meio de softwares que possibilitam o desenvolvimento do layout de um aplicativo, bem como sua programação: Android Studio ${ }^{2}$ (TAVARES, 2017); App Inventor $2^{3}$ (ELIAS, 2018). Fonseca (2017) também utilizou o software App Inventor em sua pesquisa, contudo, ele fez com que os sujeitos, alunos do $2^{\circ}$ ano do Ensino Médio, programassem seus próprios aplicativos para o estudo de sistemas de equações lineares.

Os conteúdos investigados pelos autores, a partir da utilização dos aplicativos ou dos softwares de construção de aplicativos, bem como o nível de ensino que foram contemplados nas dissertações aqui analisadas, estão descritos no Quadro 02.

Quadro 2 - Conteúdos e nível de ensino dos aplicativos identificados.

\begin{tabular}{|l|l|l|}
\hline \multicolumn{1}{|c|}{ AUTOR } & \multicolumn{1}{c|}{ CONTEÚDO ABORDADO } & \multicolumn{1}{c|}{ NÍVEL DE ENSINO } \\
\hline AMARAL, 2017 & Matemática Financeira & $3^{\circ}$ ano do Ensino Médio \\
\hline FONSECA, 2017 & Sistemas de equações lineares & $2^{\circ}$ ano do Ensino Médio \\
\hline & $\begin{array}{l}\text { Regra de três; matemática financeira; } \\
\text { moda, média e mediana; construção de } \\
\text { gráficos; integrais; derivadas; limites; } \\
\text { trigonometria; logaritmos. }\end{array}$ & $9^{\circ}$ ano do Ensino Fundamental \\
\hline HENRIQUE, 2017 & Polígonos e retas paralelas & $8^{\circ}$ e $9^{\circ}$ ano do Ensino Fundamental \\
\hline TAVARES, 2017 & Análise combinatória & $2^{\circ}$ ano do Ensino Médio \\
\hline AMIM JUNIOR, 2018 & Matemática Financeira & Não consta \\
\hline CRUZ, 2018 & Funções exponenciais & $1^{\circ}$ ano do Ensino Médio \\
\hline
\end{tabular}

${ }^{2}$ Disponível em <https://developer.android.com/studio/>. Acesso em 30 de jun. de 2019.

3 Disponível em <http://appinventor.mit.edu/explore/front.html $>$. Acesso em 30 de jun. de 2019. 


\begin{tabular}{|l|l|l|}
\hline DUARTE, 2018 & Geometria & $8^{\circ}$ ano do Ensino Fundamental \\
\hline ELIAS, 2018 & Equações do $2^{\circ}$ grau & $9^{\circ}$ ano do Ensino Fundamental \\
\hline FERNANDES, 2018 & Matemática Financeira & $3^{\circ}$ ano do Ensino Médio \\
\hline LIMA, 2018 & Geometria e algebra & $\begin{array}{l}9^{\circ} \text { ano do Ensino Fundamental e } \\
\text { Educação de Jovens e Adultos }\end{array}$ \\
\hline MACHADO, 2018 & $\begin{array}{l}\text { Teoria dos números; equações } \\
\text { diofantinas; aritmética modular; classes } \\
\text { residuais; inversos multiplicativos; } \\
\text { função de Euler }\end{array}$ & $8^{\circ}$ e $9^{\circ}$ ano do Ensino Fundamental \\
\hline NOGUEIRA, 2018 & Funções exponencial e logarítmica & $1^{\circ}$ ano do Ensino Médio \\
\hline SANTOS, 2018 & Matemática Financeira & $3^{\circ}$ ano do Ensino Médio \\
\hline SILVA, 2018 & Funções do $1^{\circ}$ e $2^{\circ}$ graus & $9^{\circ}$ ano do Ensino Fundamental \\
\hline
\end{tabular}

Fonte: dados da Pesquisa (2019).

No Quadro 02 é possível identificar que sete autores realizaram suas investigações em turmas do Ensino Médio, sete em turmas de $8^{\circ}$ e $9^{\circ}$ anos do Ensino Fundamental e um autor realizou a pesquisa em uma turma de Educação de Jovens e Adultos (EJA). Um dos autores não deixou claro o nível de ensino no qual realizou sua investigação.

Para o código "referencial teórico", houve a tentativa de identificar os nomes dos autores que tratavam sobre as tecnologias digitais no ensino, citados nas dissertações incluídas nesta pesquisa. Foi possível perceber que diferentes autores foram contemplados, mas os autores mais citados foram (i) Marcelo de Carvalho Borba: (citado por AMARAL, 2017; GERSTBERGER, 2017; HENRIQUE, 2017; CRUZ, 2018; ELIAS, 2018; FERNANDES, 2018; NOGUEIRA, 2018; e SANTOS, 2018); (ii) Vani Moreira Kenski (citada por AMARAL, 2017; GERTBERGER, 2017; ELIAS, 2018; e NOGUEIRA, 2018); (iii) José Manuel Moran (citado por AMARAL, 2017; MACHADO, 2018; NOGUEIRA, 2018; e SANTOS, 2018).

No processo de leitura dos textos aqui analisados, doi identidicado que cinco deles traziam questões relacionadas à legislação quanto ao uso de aparelhos smartphones no contexto de sala de aula (Figura 03). As leis citadas estão relacionadas aos estados nos quais os pesquisadores desenvolveram suas investigações para escrita das dissertações.

Figura 3 - Leis sobre uso de smartphones identificadas nas pesquisas
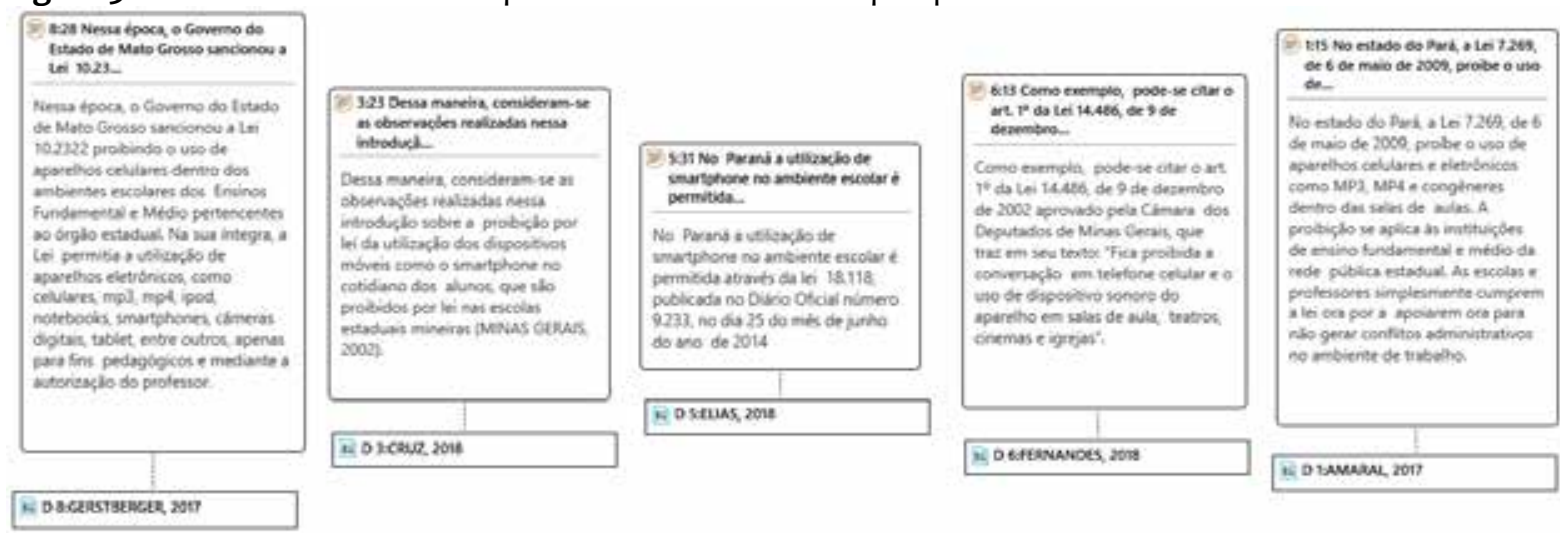

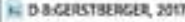
Ao o keas roie

Eo beverace, 201 
Fonte: os autores, usando ATLAS.ti (2019).

É possível identificar, na Figura 02, que quatro estados tiveram suas leis citadas: Mato Grosso (GERSTBERBER, 2017); Paraná (ELIAS, 2018); Minas Gerais (CRUZ, 2018; FERNANDES, 2018); Pará (AMARAL, 2017). Nos estados de Mato Grosso e Paraná, o uso de aparelhos smartphones é permitido, desde que esse uso tenha fim pedagógico. As legislações desses estados foram sancionadas no ano de 2014. Nos estados de Minas Gerais e Pará as leis citadas pelos autores indicam que, ainda na época da publicação das dissertações, era proibido o uso de aparelhos smartphones nas instituições escolares.

Independente dos caminhos percorridos pelos autores, na escolha da abordagem utilizada, nos aplicativos escolhidos, nos conteúdos abordados, nos níveis de ensino contemplados, nos referenciais teóricos escolhidos ou na apresentação de leis quanto ao uso de aparelhos smartphones nos estados brasileiros, os autores apontaram nos resultados de suas pesquisas, que o uso de diferentes aplicativos pode auxiliar nos processos de ensino e de aprendizagem da disciplina de Matemática. No Quadro 03 é apresentado um extrato do resumo da dissertação de alguns autores, bem como das conclusões de outros deles, nos quais fica possível identificar os resultados apresentados a partir das pesquisas que desenvolveram.

Quadro 3 - extratos de informações de algumas pesquisa

Os resultados mostraram que $\mathrm{O}$ uso do aplicativo Calculadora Financeira HP $-12 \mathrm{C}$ contribui significativamente para o ensino da Matemática Financeira e que este pode ser uma boa ferramenta pedagógica, promovendo inclusão digital, além de desmistificar a recusa irrestrita de smartphones e congêneres em sala de aula, requerendo apenas dos professores habilidades com o uso do aplicativo e uma boa compreensão sobre o momento oportuno para utilizar esse recurso (AMARAL, 2017, p. 09).

Os resultados aferidos apresentaram uma melhora em relação a motivação e também ao aproveitamento dos alunos, o que indica a viabilidade de aplicação da metodologia proposta (FONSECA, 2017, p. 07).

Cientes dos benefícios e malefícios do uso desse artefato tecnológico, os alunos se mostraram totalmente favoráveis à sua utilização dentro e fora dos ambientes escolares, alegando 'não se verem sem seus aparelhos'. Ao expressarem seu entusiasmo durante a realização das atividades, afirmaram que graças à integração dos celulares às aulas de Matemática estas se tornaram mais 'dinâmicas e atraentes', levando-os a uma melhor compreensão e apreço em estudar essa disciplina (GERSTBERGER, 2017, p. 147).

Como contribuições do smartphone na implementação de atividades, destacamos o apelo motivador que este recurso traz às aulas. Particularmente, no trabalho com retas paralelas cortadas por transversais, o uso GeoGebra aplicativo mostrou-se instigante por permitir aos alunos a observação de um conjunto de elementos (ângulos, posição de retas etc.) variantes ou invariantes e, juntamente com o manuseio e exploração das formas manuseadas. Como desafios é possível apontar a dificuldade de visualização de propriedades em um constructo para casos em que a tela do smatphone é pequena (HENRIQUE, 2017, n.p.)

Por meio deste estudo foi possível verificar que novas metodologias de ensino aliadas ao uso de tecnologias, podem contribuir para o ensino de Matemática, especialmente para o de Análise 
Combinatória (TAVARES, 2017, p. 13).

Isto permitiu observar a capacidade de autonomia dos alunos na escolha dos aplicativos e o desenvolvimento do olhar crítico ao analisar taxas de juros e opções de pagamentos, servindo como alicerce para a construção de uma educação financeira a ser usada no dia a dia (AMIM JUNIOR, 2018, p. 7).

O principal resultado desse estudo mostrou que os dispositivos móveis como os telefones celulares e os smartphones foram utilizados como instrumentos mediáticos entre os participantes desse estudo, a professora-pesquisadora e os conteúdos relacionados com funções exponenciais, que foram trabalhados por meio do software GeoGebra, que foi baixado nesses dispositivos móveis. Assim, essa mediação potencializou o desenvolvimento de habilidades matemáticas referentes à identificação de conceitos e propriedades de funções exponenciais, bem como determinar as características de seus gráficos (CRUZ, 2018, p. 8).

Como desafio o estudo aponta a falta de hábito dos estudantes em realizar atividades que utilizam a escrita e reflexões constantes sobre as mesmas. Como contribuições destaca o uso do GeoGebra App e do smartphone como recursos motivadores e desafiantes para a aula e para o aprendizado. A dinamicidade do software permite, além de observações articuladas dos conceitos previstos nas tarefas, outras inesperadas, por exemplo, a de ângulos replementares. A investigação ressalta a importância de aulas interativas e dinâmicas com o uso de softwares e de atividades diversas no Ensino Fundamental (DUARTE, 2018, p. 3).

Percebemos que é possível promover um ambiente diferenciado em sala de aula a partir do uso de aparelhos smartphones e, identificamos no software App Inventor um auxílio para a inserção desta ferramenta na disciplina de Matemática. Os conceitos que os estudantes tinham trabalhado sobre o conteúdo de Equações do $2^{\circ}$ Grau serviram de subsunçores para a aquisição de novos significados em relação ao mesmo, de tal maneira, que a Aprendizagem Significativa aconteceu efetivamente durante esta pesquisa (ELIAS, 2018, p. 6).

Enfim, retomando a questão de investigação posta, notou-se que os dispositivos móveis podem contribuir de diversas maneiras em tarefas que envolvam a tomada de decisão sobre assuntos financeiros. Seja através de aplicativos que possibilitam simular situações, buscadores que permitem ao aluno obter mais informações através da internet, mensageiros virtuais que permitem a grupos de alunos continuar conversando sobre a tarefa mesmo distantes fisicamente, entre outras possibilidades. Isto é, esta pesquisa não esgotou a variedade de formas com que os dispositivos móveis podem contribuir em tarefas, mas aqui são colocadas apenas algumas possibilidades para que se possa refletir sobre a tecnologia móvel como uma alternativa para que as TICs sejam de fato inseridas, ou deixem de ser esporádicas, na pratica do professor de matemática com suas turmas (FERNANDES, 2018, p. 62).

Verificou-se, em última instância, que os aplicativos móveis se constituem em importantes aliados na facilitação do processo ensino e aprendizagem da matemática na educação básica, contribuindo para motivar, dotar de autonomia e tornar mais agradável o ensino de Matemática na educação básica (LIMA, 2018, p. 5).

Concluiu-se um resultado satisfatório tendo em vista o retorno dado pelos alunos (registrado em forma de questionário) e as novas possibilidades que contribuirão ainda mais com a formação deste professor (MACHADO, 2018, p. 7).

As respostas obtidas nas atividades e as opiniões dos alunos nos levaram a verificar que a Calculadora Gráfica GeoGebra realmente foi capaz de facilitar a compreensão do conteúdo trabalhado, além de aumentar o interesse dos alunos, sendo uma ferramenta de grande potencial que serve de benefício para o trabalho do docente e para o aprendizado do aluno (NOGUEIRA, 2018, p. 6).

[...] concluímos que é enriquecedor o uso de ferramentas tecnológicas, como o aplicativo mencionado, no ensino de matemática. Fato que revela a pertinência em atrelar as tecnologias disponíveis hoje em dia, ao processo de ensino, a fim de torná-lo mais significante e contextualizado, proporcionando assim, a construção de conhecimento de maneira mais atrativa, menos cansativa e mais eficiente (SANTOS, 2018, p. 7).

Os resultados mostram que os aparelhos smartphones têm conquistado espaço dentro das escolas e que podem ser utilizados como recurso para aprendizagem, desde que acompanhado pelo docente baseado 
em um planejamento estratégico (SILVA, 2018, p. 3).

Fonte: os autores (2020).

Nas citações de todos os autores, apresentadas no Quadro 03 é possível perceber que o uso dos aparelhos smartphones utilizados em sala de aula pode auxiliar no processo de aprendizado de diferentes conteúdos nas aulas de Matemática. Nesse viés, vale a pena se debruçar em novas leis e novos estudos sobre o uso desses aparelhos, de maneira a auxiliar os estudantes na compreensão do conteúdo de Matemática e ainda, verificar a necessidade de utilização desse recurso em aulas de outras disciplinas e até mesmo aulas interdisciplinares.

\section{CONSIDERAÇÕES FINAIS}

$\mathrm{Na}$ análise dos trabalho selecionados, foi possível perceber diferentes possibilidades para o uso de aparelhos smartphones no contexto educacional de Matemática. Neles, identificamos que o papel do professor ao utilizar tal tecnologia, é de mediador do processo de aprendizado, isto se ele for um profissional que visa atender as necessidades dos estudantes da atualidade.

Portanto, é fundamental que haja um planejamento prévio para o uso pedagógico de smartphones em sala de aula. Esse planejamento deve acontecer de tal maneira, que o profissional da educação preocupe-se em atingir os objetivos curriculares, pedagógicos e também sociais pois, os estudantes estão inseridos em diferentes ambientes e merecem um olhar holístico dos setores educacionais, tanto na esfera pública como na privada.

Foi possível perceber que houve um predomínio de práticas que valorizavam a utilização de aplicativos. Dentre os 32 citados, o GeoGebra apareceu em seis pesquisas. Diante desse fato, fica notável que existem possibilidades de investigar outras formas para o uso de tais aparelhos em sala de aula, mediante aplicativos e outras funcionalidades para exploração de diferentes conteúdos matemáticos.

Outra observação recai na realização da revisão sistemática em dissertações de mestrados acadêmicos no Banco de Teses e Dissertações da Capes. Neste, foi identidicado que existe uma lacuna à respeito de trabalhos de teses que abordem o uso de aparelhos smartphones no meio educacional. Também ficou evidente a necessidade de realização de pesquisas quanto a usabilidade de smartphones para turmas do Ensino Fundamental I e para 
turmas de $6^{\circ}$ e $7^{\circ}$ anos do Ensino Fundamental II. Dessa forma, ainda há novos caminhos a serem percorridos em pesquisas sobre o uso de tais tecnologias em sala de aula.

Já em relação a legislação, quanto ao uso de smartphones em sala de aula, elas devam ser divulgadas e conhecidas pelos profissionais que atuam em diferentes esferas educacionais. É possível que se mais pesquisadores identificarem que a utilização pedagógica desses aparelhos auxilia nos processos de ensino e de aprendizagem em sala de aula, outros estados podem rever as leis quanto ao seu a usabiliade desses recursos dentro das instituições educacionais.

Nas dissertações analisadas, foi possível verificar em seus referenciais teóricos que os autores mais citados foram Borba, Kenski e Moran. Logo, as obras e estudos de tais autores podem servir como referências para futuras pesquisas sobre o uso de tecnologias digitais no contexto educacional.

Por fim, é sugerido uma continuação em pesquisas sobre o uso de aparelhos smartphones no contexto educacional. Também, é possível realizar uma análise quanto as percepções de professores da Educação Básica diante das possibilidades de uso desses aparelhos, não somente nas aulas de Matemática, mas em outras disciplinas.

\section{REFERÊNCIAS}

ALMEIDA, C. M. M.; SCHEUNEMANN, C. M. B.; SANTOS, M. J.; LOPES, P. T. C. Propuestas de metodologías activas utilizando tecnologías digitales y herramientas metacognitivas para auxiliary en el processo de eneñanza y aprendizaje. Revista Paradigma. v. 40, n. 1, 2019. p. 204-220.

AMARAL, G. S. Calculadora financeira HP-12C em smartphones como recurso didático para o ensino de matemática no ensino médio. Dissertação (Mestrado Profissional em Matemática em Rede Nacional). Santarém: Universidade Federal do Oeste do Pará, 2017.

AMIM JÚNIOR, J. E. Tomada de decisões e o aprendizado de matemática financeira: uma experiência com aplicativos para smartphone. Dissertação (Mestrado Profissional em Matemática em Rede Nacional). Goiânia: Universidade Federal de Goiás, Instituto de Matemática e Estatística, 2018.

ATLAS.ti, versão 8. Qualitative data analysis software. Alemana: ATLAS.ti, 2019.

BORBA, M. C.; Silva, R. S. R.; GADANIDIS, G. Fases das tecnologias digitais em educação matemática: sala de aula e Internet em movimento. $1^{\mathrm{a}}$ ed. Belo Horizonte: Autêntica, 2005.

BORBA, M. C.; LACERDA, H. D. G. Políticas públicas e tecnologias digitais: um celular por aluno. Educação Matemática Pesquisa, São Paulo, v. 17, n. 3, 2015. p. 490-507. 
CRUZ, A. M. Potencialidades da utilização do software GeoGebra para o desenvolvimento do conteúdo de funções exponenciais através do smartphone. Dissertação (Mestrado em Educação Matemática). Outro Preto: Universidade Federal de Ouro Preto, 2018.

DUARTE, R. C. B. C. Utilização do GeoGebra, de smartphone e de reflexões escritas na construção de conceitos relacionados a retas paralelas cortadas por uma transversal. Dissertação (Mestrado em Educação em Ciências e Matemática). Seropédica: Universidade Federal Rural do Rio de Janeiro, 2018.

ELIAS, A. P. A. J. Possibilidades de utilização de smartphones em sala de aula: construindo aplicativos investigativos para o trabalho com equações do $2^{\circ}$ grau. Dissertação (Mestrado em Ensino de Ciências e Matemática). Curitiba: Universidade Tecnológica Federal do Paraná, 2018.

FERNANDES, F. D. A. Dispositivos no ensino de educação financeira escolar: análise e aplicação de tarefas. Dissertação (Mestrado Profissional em Educação Matemática). Juiz de Fora: Universidade Federal de Juiz de Fora, 2018.

FONSECA, R. A. Uso de princípios básicos de programação como alternativa para o ensino de sistemas lineares e matrizes no ensino médio. Dissertação (Mestrado Profissional em Matemática em Rede Nacional). Seropédica: Universidade Federal Rural do Rio de Janeiro, 2017.

FREITAS, R. O.; CARVALHO, M. Tecnologias móveis: tablets e smartphones no ensino da matemática. Laplage em Revista, Sorocaba. v. 3, n. 2, 2017. p. 47-61.

GESTERBERG, A. Um olhar etnomatemático acerca da utilização dos smartphones nos processos de ensino de matemática nos anos finais do ensino fundamental. Dissertação (Mestrado Profissional em Ensino de Ciências Exatas). Lajeado: Centro Universitário Univates, 2017.

HENRIQUE, M. P. GeoGebra no clique e na palma das mãos: contribuições de uma dinâmica de aula para construção de conceitos geométricos com alunos do Ensino Fundamental. Dissertação (Mestrado em Educação em Ciências e Matemática). Seropédica: Universidade Rural do Rio de Janeiro, 2017.

HESS, L. W. B.; ASSIS, R. M. N.; VIANA, H. B. Inserção das tecnologias digitais na prática docente. Laplage em Revista, Sorocaba. v. 5, n. 2, 2019. p. 119-127.

LIMA, R. J. S. Uso do software livre GeoGebra no smartphone como ferramenta de ensino e aprendizagem. Dissertação (Mestrado Profissional em Matemática em Rede Nacional). Belém: Universidade Federal do Pará, 2018.

MACHADO, A. P. Teoria dos números e criptografia RSA: uma proposta de ensino para alunos de matemática olímpica. Dissertação (Mestrado Profissional em Matemática em Rede Nacional). Santa Maria: Universidade Federal de Santa Maria, 2018. 
MALTEMPI, M. V. Novas tecnologias e construção de conhecimento: reflexões e perspectivas. In: Congresso Ibero-Americano de educação matemática. Anais... Cidade do Porto, 2005.

MENDES, A. A. P.; CHAMPAOSKI, E. B. Percepção de professors do ensino fundamental I acerca das tecnologias digitais no cotidiano escolar. Revista Intersaberes. v. 12, n. 26. 2017. p. 415-430.

NOGUEIRA, E. L. P. O uso da calculadora gráfica GeoGebra no smartphone como ferramenta para o ensino das funções exponencial e logarítmica. Dissertação (Mestrado Profissional em Matemática em Rede Nacional). Natal: Universidade Federal do Rio Grande do Norte, 2018.

RAMOS, A.; FARIA, P. M.; FARIA, A. Revisão sistemática de literatura: contributo para a inovação na investigação em ciências da educação. Revista Diálogo Educacional. v. 14, n. 41, 2014. p. 17-36.

ROMANELLO, L. A. Potencialidades do uso do celular na sala de aula: atividades investigativas para o uso de função. Dissertação (Mestrado em Educação Matemática). Rio Claro: Universidade Estadual Paulista, 2016.

SANTOS, A. L. O uso da calculadora do cidadão e smartphones como ferramenta didática no ensino da matemática financeira no ensino médio. Dissertação (Mestrado Profissional em Matemática em Rede Nacional). Ilhéus: Universidade Estadual de Santa Cruz, 2018.

SILVA, E. R. P. A utilização do aplicativo geogebra para smartphone como recurso didático nas aulas de matemática do ensino fundamental. Dissertação (Mestrado Profissional em Matemática em Rede Nacional). São Luís: Universidade Federal do Maranhão, 2018.

TAVARES, P. C. M. Ensino da análise combinatória por meio de um aplicativo para Android. Dissertação (Mestrado em Ensino de Ciências e Matemática). Belo Horizonte: Pontifícia Universidade Católica de Minas Gerais, 2017.

URBANO, M. C.; FARÍAS, D.; PÉREZ, J. Blog como herramienta tecnológica de apoyo en la enseñanza de la matematica en áreas administrativas. Revista Pradigma, v. 40, n. 2, 2019. p. 176-195.

VOSGERAU, D. S. R.; ROMANOWSKI, J. P. Estudos de revisão: implicações conceituais e metodológicas. Revista Diálogo Educacional. v. 14, n. 474, 2014. p. 165-189.

WALTER, S. A.; BACH T. M. Adeus papel, marca-textos, tesoura e cola: inovando o processo de análise de conteúdo por meio do ATLAS. ti. Administração: ensino e pesquisa, v. 16, n. 2 , 2015. p. 275-308.

Recebido em: 19/10/2020

Parecer em: 29/02/2020

Aprovado em: 08/03/2021 